\title{
Questões sobre o desenvolvimento de crianças em situação de rua
}

\author{
Claudio Simon Hutz e Sílvia Helena Koller \\ Universidade Federal do Rio Grande do Sul
}

\begin{abstract}
A Psicologia e a pesquisa científica não oferecem respostas satisfatórias para várias questões relativas ao desenvolvimento de crianças em situação de rua. Alguns estudos afirmam que o viver na rua é prejudicial, ou retarda o desenvolvimento psicológico, devido às experiências a que estas crianças estão expostas, como adições, violência e exploração. Outros estudos mostram que a rua possibilita vivências cumulativas que promovem o desenvolvimento. Estes achados incongruentes indicam a necessidade de se realizar mais estudos nesta área. O CEP-RUA/UFRGS vem desenvolvendo vários estudos sobre o desenvolvimento emocional, cognitivo e social destas crianças. Os resultados destes estudos têm revelado que crianças em situação de rua apresentam altos níveis de stress e de exposição a riscos pessoais e sociais. Porém, constatamos que elas desenvolvem habilidades para lidar com o stress e com os riscos, compensando suas dificuldades com estratégias que exigem competência e autonomia. Uma das estratégias utilizadas relaciona-se aos agrupamentos afetivos, econômicos e sociais, por meio dos quais garantem sua sobrevivência e segurança. As crianças testadas pelos pesquisadores do CEPRUA não apresentam índices de depressão e de sofrimento psicológico mais elevados do que crianças de nível sócioeconômico baixo. Testadas quanto ao seu bem-estar subjetivo, elas também não diferem significativamente de outros grupos. Estudos realizados para investigar eventos de vida
\end{abstract}


e emoções revelam histórias intrigantes sobre suas trajetórias e sensibilidade. Porém, uma alternativa para um lar que garanta um desenvolvimento saudável para as crianças que estão na rua deve ser encontrada. Mesmo que não cause grande dano psicológico, a rua não é um lugar saudável para qualquer ser humano viver.

Palavras-chave: Crianças em Situação de Rua, Crianças em situação de Risco, Desenvolvimento.

$\mathrm{O}$ objetivo deste estudo é discutir alguns aspectos do desenvolvimento de crianças e adolescentes em situação de rua. Embora a Psicologia do Desenvolvimento tenha acumulado muito conhecimento sobre crianças em geral, há uma grande lacuna quando se enfoca indivíduos em situação de risco pessoal e social (Emde, 1994; Huston, McLoyd, \& Coll, 1994). Jessor (1993) chama a atenção para a falta de modelos teóricos e pesquisa empírica sobre o desenvolvimento de crianças e adolescentes que vivem em situação de pobreza, por exemplo. Vários autores têm lamentado a falta de atenção dada ao estudo do desenvolvimento de seres humanos, que vivem na pobreza ou fazem parte de minorias étnicas ou raciais (Fischer, 1993). Suas queixas referemse à virtual inexistência de estudos evolutivos com segmentos minoritários da população norte-americana. Referem-se, ainda, ao fato de que a grande maioria dos estudos normativos sobre desenvolvimento psicológico tem sido feita com crianças e adolescentes brancos de classe média, que vivem, principalmente nas proximidades das universidades. Dizem, com razão, que continua-se a estudar o desenvolvimento normal das crianças brancas de classe média e a patologia dos negros, dos hispânicos, dos imigrantes e dos pobres em geral. No Brasil, este quadro repete-se, com o agravante de que, apesar do grande número de problemas sociais que o país enfrenta, os estudos em Psicologia sobre indivíduos expostos aos riscos provocados por estes problemas têm merecido pouca atenção.

Vamos tentar aqui descrever alguns estudos da literatura na área e procurar indicar algumas prioridades para a pesqui- 
sa em psicologia do desenvolvimento com estas populações, enfatizando achados do Centro de Estudos Psicológicos sobre Meninos e Meninas de Rua (CEP-RUA), da Universidade Federal do Rio Grande do Sul, que vem se dedicando a pesquisar sobre este tema.

Inicialmente, precisamos definir o que é risco. Uma criança será considerada em situação de risco quando seu desenvolvimento não ocorre de acordo com o esperado para sua faixa etária de acordo com os parâmetros de sua cultura (Bandeira, Koller, Hutz, \& Forster, 1996). O risco pode ser físico (doenças genéticas ou adquiridas, prematuridade, problemas de nutrição, entre outros), social (exposição a ambiente violento, a drogas) ou psicológico (efeitos de abuso, negligência ou exploração). O risco pode ser originado por causa externa ou interna. As causas externas relacionam-se às condições adversas do ambiente. Comportamentos de risco referem-se a ações ou atividades realizadas por indivíduos que aumentam a probabilidade de consequiências adversas para seu desenvolvimento ou funcionamento psicológico ou social, ou ainda que favorecem o desencadeamento ou agravamento de doenças. Porém, para identificar um "aumento na probabilidade" é necessário conhecer a probabilidade das mencionadas "consequiências adversas" na população geral. Isso aponta para a importância de desenvolver estudos descritivos e epidemiológicos com os diferentes segmentos da população.

Uso de drogas (lícitas ou ilícitas), comportamento sexual promíscuo, relações sexuais desprotegidas, família desestruturada, falta de modelos apropriados, socialização inadequada para promover o respeito pela vida e pela dignidade dos seres humanos, etc., são fatores que colocam em situação de risco, crianças e adolescentes em todas as classes sociais, inclusive nos países desenvolvidos. No Brasil, quem conhece a realidade das melhores escolas de segundo grau do país, ou quem observa o comportamento de adolescentes ricos nas madrugadas nas grandes cidades, tem pouca dúvida de que não são apenas os filhos dos pobres que estão em situação de risco. A situação não é muito melhor em outros países. Dryfoos (1990) realizou estudos epidemiológicos usan- 
do uma escala de avaliação de exposição a situações de risco e concluiu que cerca de metade dos adolescentes norte-americanos encontra-se em situação de risco moderado a elevado. Esta estimativa parece ser um exagero, porém tem sido confirmada por outros estudos (Kazdin, 1993).

O espectro de riscos é bastante amplo. Todavia, vamos restringir o escopo deste artigo a populações que apresentam, entre outros, um fator de risco universal: a miséria. Mais especificamente, vamos examinar a literatura referente a crianças em situação de rua (para maior discussão sobre a definição de criança de/na rua ver Koller \& Hutz, 1996). Crianças de rua são um segmento especial e não representativo de toda a população de risco, mas que tem recebido considerável atenção de pesquisadores, especialmente na última década, impulsionada pelo fenômeno crescente dos homeless nos Estados Unidos. No Brasil, alguns estudos têm enfocado questões psicológicas sobre as crianças de rua. Como mencionamos em outro estudo (Koller \& Hutz, 1996), o viver na rua pode ser prejudicial ou retardar o desenvolvimento psicológico, devido às experiências adversas a que estas crianças estão expostas, como adições, violência e exploração. Paradoxalmente, a vida na rua pode possibilitar experiências que se adicionam e promovem o desenvolvimento. No entanto, estes achados são incongruentes e revelam a necessidade de se realizar mais estudos nesta área.

Meninos de rua não são novidade no Brasil ou na história universal. A primeira história relatada sobre um menino de rua parece ter sido contada em 1554, em uma novela autobiográfica, intitulada La vida de Lazarillo de Tormes y de sus fortunas y adversidades (Koller \& Hutz, 1996). No Brasil, alguns relatos do período colonial e da época da abolição da escravatura referem-se a crianças abandonadas na rua. Atualmente há algumas centenas de livros e artigos, além de listas eletrônicas e sites na Internet, que abordam a problemática de crianças, adolescentes, famílias e pessoas em geral que vivem nas ruas em dezenas de países, em todos os continentes. Tyler e colaboradores (1987) apontaram para o fato de que crianças de rua são um fenômeno mundial, embora de inci- 
dência variada e dependente, em grande parte, mas não exclusivamente, das condições sócio-econômicas da sociedade (Tyler, Holliday, Tyler, Echeverry, \& Zea, 1987). Koller e Hutz (1996) acrescentaram à miséria econômica uma miséria afetiva, como antecedente à saída da criança para a rua.

\section{Desenvolvimento social de crianças em situação de rua}

Desenvolvimento social é uma área multidisciplinar de grande amplitude que estuda a interação de fatores maturacionais e ambientais no desenvolvimento da capacidade de um indivíduo em manter relações sociais e os efeitos destas relações sobre seu desenvolvimento psicológico em geral, inclusive sobre sua capacidade de manter relações sociais. O processo de desenvolvimento social é individual e não ocorre exatamente da mesma forma para duas pessoas. Seu estudo consiste, portanto, na procura de padrões comuns, de regularidades no desenvolvimento. Este desenvolvimento é fundamental para a sobrevivência dos indivíduos e indispensável para a vida na sociedade. O valor de sobrevivência e a vantagem reprodutiva propiciada por alguns destes processos torna inevitável sua ocorrência em todas as culturas. Alguns mecanismos de interação social são programados geneticamente, tais como a capacidade para desenvolver relações afetivas e apego, por exemplo.

Porém, se a determinação biológica obriga seres humanos a interagir, pelo menos durante grande parte de suas vidas, são os fatores ambientais, em interação com fatores maturacionais e de personalidade, que determinarão, em grande parte, como essa interação irá ocorrer e seus efeitos para o desenvolvimento psicológico e o bem-estar dos indivíduos.

A estereotipia e o preconceito da sociedade com relação às crianças em situação de rua vem sendo descritos na literatura em geral. Crianças de rua têm sido descritas como marginais, doentes, violentas, sujas e delinqüentes (Aptekar, 1989; Marguerat, 1989; McKirnan \& Jonhson, 1986). Silva, Weber, Raimundo, Bandeira e Koller (1996) investigaram, através do desenho da figura humana, como as crianças de rua e de nível sócio-econômico médio-alto representam a si mesmas 
e ao outro grupo. Foram testadas 39 crianças em situação de rua e 148 crianças que freqüentavam uma escola particular. Foi solicitado às crianças que primeiro desenhassem uma Figura Humana, sendo primeiro a representação de si mesmos e depois de uma criança do outro grupo. Os desenhos foram avaliados por dois juízes cegos para as características das crianças que executaram os desenhos. Foi realizado um levantamento de categorias para descrever o desenho analisado. As categorias observadas nos desenhos foram: expressão facial, presença/ausência de sapatos, de mãos, e de roupas, aparência geral (sujo/limpo), postura, cenário, acessórios e objetos nas mãos. A comparação entre os desenhos revelou muitos aspectos estereotipados. As crianças de rua foram representadas pelas de escola como sujas, negras, mal vestidas e sem sapatos, com roupas rasgadas, carregando drogas nas mãos e pedindo esmolas em esquinas, às vezes sentados ou deitados. As crianças de escola foram representadas pelos de rua como bem-vestidas e calçadas, limpas, de pé e carregando sacos de dinheiro nas mãos. Quando desenham a si mesmos, as crianças de ambos os grupos fazem desenhos de figuras humanas alegres, vestidas, limpas, com sapatos, sem objetos nas mãos, de pé e de frente e com acessórios. Estes resultados revelam a discrepância entre como as crianças em situação de rua se vêem ou gostariam de ser vistos e como são vistas pelas crianças das escolas.

Crianças em situação de rua são seres humanos em desenvolvimento, que podem apresentar algumas características psicológicas sadias, apesar das dificuldades impostas por um ambiente hostil. Para manterem-se na rua, desenvolvem estratégias para lidar com circunstâncias que podem expô-las a riscos e podem torná-las vulneráveis. Esta afirmação aponta para duas direções opostas. A vida na rua gera altos níveis de stress, riscos freqüentes e intensos e testam permanentemente a vulnerabilidade emocional, social, física e cognitiva/educacional desta criança. No entanto, exigem que ela seja resiliente e desenvolva estratégias, tenha forças para lidar com o infortúnio e para se adaptar (Donald \& Swart-Kruger, 1994). A Tabela 1 apresenta áreas de desenvolvimento social, que 
apresentam riscos à estas crianças e algumas estratégias que utilizam para continuar se desenvolvendo.

Tabela 1. Desenvolvimento Social: Vulnerabilidade e adaptabilidade em crianças em situação de rua

\begin{tabular}{|c|c|c|}
\hline $\begin{array}{l}\text { Área de desenvolvimento } \\
\text { SOCIAL }\end{array}$ & $\begin{array}{c}\text { Evidência de } \\
\text { risco ou vulnerabilidade }\end{array}$ & $\begin{array}{c}\text { Evidência de } \\
\text { adaptabilidade ou } \\
\text { estratégia }\end{array}$ \\
\hline 1. Identidade social & $\begin{array}{l}\text { - } \text { exclusão } \\
\text { - estereotipia e preconceito }\end{array}$ & $\begin{array}{l}\text { - busca de oportunidades } \\
\text { - desejo de superação }\end{array}$ \\
\hline 2. Relações de amizade & $\begin{array}{l}\text { - oportunismo } \\
\text { - instabilidade }\end{array}$ & $\begin{array}{l}\text { - } \text { estabelecimento de } \\
\text { vínculos } \\
\text { - cuidados mútuos } \\
\text { - reciprocidade }\end{array}$ \\
\hline
\end{tabular}

Um dos aspectos fundamentais ao desenvolvimento social relaciona-se com o senso de pertinência e identidade social. A realidade a que as crianças em situação de rua estão expostas, denuncia sua exclusão e marginalidade. Koller (1994) fez um estudo sobre o desenvolvimento moral prósocial de crianças de rua no qual perguntava sob que condições elas ajudariam potenciais receptores de ajuda que pedissem sua ajuda. Não raro, a resposta destas crianças vinha carregada de um senso claro de exclusão, com expressões como: "quem vai querer a ajuda de um menino de rua?", ou "quem vai acreditar que a gente está chegando perto para ajudar?". Além da exclusão, estas crianças estão expostas ao crime ou à violência da rua. Uma estratégia para superar essas dificuldades é estabelecer relações de amizade que sejam protetivas, mesmo que instáveis e erráticas, mas que possibilitem alguns cuidados mútuos e reciprocidade. Koller e Hutz (1996) mencionam algumas formas de agrupamento destas crianças, desenvolvendo relações de afeto, de trabalho e uma certa moralidade e regras no grupo. Koller (1994) também observou um alto índice de reciprocidade relacionada a comportamentos de ajuda, entre estas crianças. Com o intuito de entender melhor esta questão, vários estudos estão sendo de- 
senvolvidos pelo CEP-RUA e podem ser mencionados. Em estudos recentes, Raffaelli e colaboradores (Raffaelli, Koller, Reppold, Kuschik, \& Bandeira, 1997; Raffaelli, Koller, Bandeira, Reppold, Kuschick, \& Dani, 1997) identificaram vários eventos de risco pessoal e social na vida de crianças de rua de 12 a 17 anos de idade. Os participantes de ambos os estudos revelaram uso de drogas, prática de sexo sem preservativo, diversos tipos de acidentes etc. Por outro lado, demonstraram várias habilidades para lidar com estes riscos, compensando suas dificuldades com estratégias que exigem competência e autonomia. Uma das estratégias utilizadas relaciona-se aos agrupamentos afetivos, econômicos e sociais, por meio dos quais garantem sua sobrevivência e segurança. Outra estratégia refere-se à busca do auxílio em instituições e de benfeitores para a solução de problemas prementes. Alguns sujeitos, para os quais foi oferecida uma oportunidade, relataram que esforçaram-se para aproveitá-la e melhorar sua condição de vida.

Kuschick, Reppold, Dani, Raffaelli e Koller (1996) em um estudo, no qual investigaram a visão dos meninos de/na rua a respeito de sua situação de vida e as estratégias que estes utilizam para enfrentar as dificuldades cotidianas desde a saída de casa até a condição atual, demonstraram que 58 sujeitos na cidade de Porto Alegre (34 e 24), de 11 a 17 anos, encaram suas vidas como arriscadas e duras, mas contam com as instituições para superar algumas dificuldades. Kuschick e colaboradores (1996) utilizaram uma entrevista semiestruturada que abrangia tópicos como: "vida na rua", "atividade do dia", "atividade da noite" e "eventos de vida". A análise do conteúdo das respostas sobre o viver na rua revelou que os meninos têm mais opiniões negativas (71\%) com relação à vida na rua do que as meninas (58\%). Os meninos revelaram receber menos ajuda $(72 \%)$ do que as meninas $(84 \%)$, seja da família ou de pessoas na rua. Dentre as atividades diárias, os meninos destacaram "ficar em instituições" (75\%), "estudar" (41\%), "vagar pela rua" (22\%) e "trabalhar" (19\%). As meninas referiram "ficar em instituições" (58\%), "lazer" e "estudar" (37\%) e "vagar pela rua" (32\%). Dentre as ativi- 
dades da noite, os meninos revelaram utilizar-se mais do espaço da rua para "dormir" $(60 \%)$, enquanto as meninas procuram as instituições $(47 \%)$ e a família $(21 \%)$ para abrigo noturno. Mesmo assim, as meninas sentem-se menos seguras nessas condições (57\%). Com relação aos eventos de vida, os meninos relataram sofrer mais acidentes $(68 \%, 53 \%)$, maior uso de drogas $(81 \%, 63 \%)$, sentir mais fome $(66 \%, 48 \%)$, roubar $(50 \%, 37 \%)$ e sofrer mais abuso físico pela polícia $(66 \%, 32 \%)$ do que as meninas. Os dados revelaram que os meninos recebem menos ajuda, transgridem mais as regras sociais e avaliam sua situação como mais crítica do que as meninas. Esses achados reforçam a posição de que cada sexo encontra estratégias de ação diferentes quando se deparam com problemas da mesma natureza e estão expostos a situações de risco diferenciadas.

\section{Desenvolvimento Cognitivo de crianças em situação de rua}

A vivência de rua, certamente, proporciona experiências diferenciadas às crianças, que não são similares às das crianças que vivem sob a proteção permanente de uma família ou mesmo àquelas que frequientam diariamente a escola. Os vários estímulos que a rua apresenta, exigem que a criança esteja atenta e preparada para manter a sua integridade física e sua sobrevivência. Esta atividade permanente, em um âmbito tão diferenciado e provocador, deve gerar desequilíbrios cognitivos e necessidade de equilibração constante. Alguns estudos afirmam que ao invés de provocar um retardo no desenvolvimento cognitivo, a vida na rua facilita e promove o desenvolvimento (Aptekar, 1989; 1996). No Brasil, Carraher e colaboradores (1985) revelaram que crianças trabalhadoras de rua podem ter uma aprendizagem natural da matemática, que a escola não é capaz de propiciar. Além de habilidades matemáticas, outros aspectos cognitivos foram avaliados, como o nível de julgamento moral. Barreto (1991) verificou que o raciocínio moral de crianças de rua, quando comparado ao de crianças de mesma idade que vivem com suas famílias, não difere significativamente. Koller (1994) também verifi- 
cou que crianças em situação de rua, que não freqüentam escolas, raciocinam pró-socialmente no mesmo nível que crianças escolares da mesma faixa etária. Ou seja, conforme concluem Koller e Hutz (1996, p.14), "o viver na rua não impede o desenvolvimento de valores e não gera deficiências morais específicas em crianças e adolescentes".

A Tabela 2 apresenta alguns aspectos que indicam vulnerabilidade de crianças em situação de rua, do ponto de vista cognitivo, e algumas estratégias utilizadas para superar estas dificuldades.

Tabela 2. Desenvolvimento Cognitivo: Vulnerabilidade e adaptabilidade em crianças em situação de rua

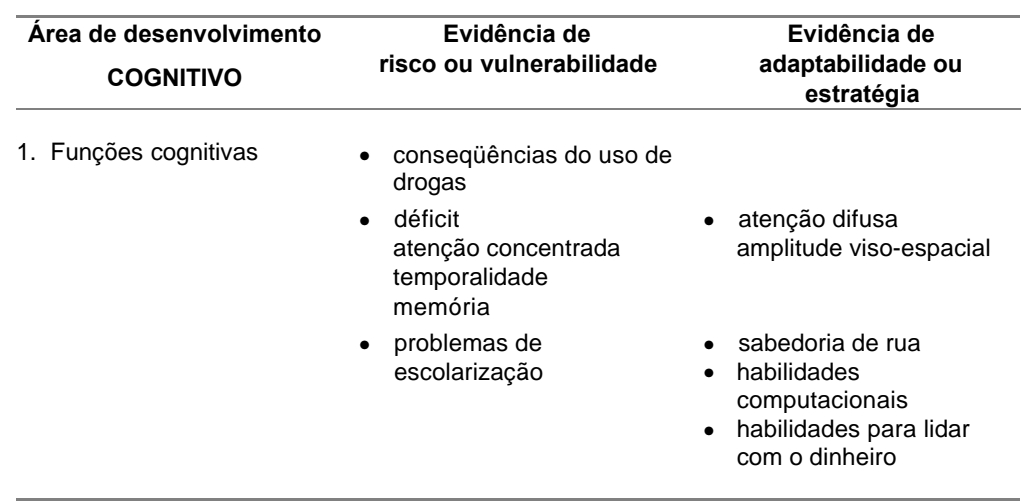

As funções cognitivas podem estar afetadas, por exemplo, pelo uso frequiente e destrutivo de drogas que muitas destas crianças fazem, às vezes de forma permanente (Forster, Barros, Tanhauser, \& Tanhauser, 1992). Não parece haver estratégia que supere esta vulnerabilidade. No entanto, sabese que na presença de uma oportunidade e com uma política social mais eficiente (no sentido de coibir a distribuição de drogas) as dificuldades acumuladas poderiam ser superadas, pelo menos em parte. Uma das drogas mais usadas e perigosas que ameaçam a saúde destas crianças, denominada "loló", não é considerada ilícita e sua venda não tem sido proibida pela polícia das grandes cidades, embora o prejuízo causado por ela seja devastador do ponto de vista físico e psicológico. 
Outro aspecto cognitivo importante está relacionado à função psicológica da atenção. Em seus trabalhos de campo, as equipes do CEP-RUA observam que estas crianças apresentam dificuldade de prender a atenção em alguma tarefa mais específica por um período de tempo maior. Esta dificuldade não pode ser identificada como problema cognitivo de atenção concentrada. Considera-se que a função esteja preservada, especialmente se considerarmos a amplitude viso-espacial e a capacidade de atenção difusa destas crianças. Elas estão atentas a todos os estímulos que a rua apresenta, como uma forma de defesa pessoal, como se tivessem radares ou antenas para detectarem estímulos que passam desapercebidos ao transeunte comum. No entanto, seja por falta de hábito de se concentrar em uma tarefa específica (fato relacionado à falta de escolarização), seja por uso de drogas, a atenção concentrada parece não colaborar para a finalização de algumas tarefas.

A função da memória também apresenta algumas dificuldades. O uso de drogas pode ser responsável por este déficit. No entanto, a questão da temporalidade parece ser muito importante nesta questão. Tem-se observado que as crianças apresentam muita dificuldade de lembrar com clareza, qualquer evento que esteja relacionado com a medição do tempo. Esta falta de clareza revela-se nas respostas incomuns a perguntas que exigem conhecimento do sistema de medida de tempo convencional. Em geral, não sabem quanto tempo faz que estão na rua, que visitaram a família pela última vez, em que dia da semana se encontram, que hora do dia é agora, entre outras. Sem contar com a carga emocional que algumas destas questões pode abarcar, as dificuldades com o conceito de tempo podem estar relacionadas com a falta de rotina e de sistemas disponíveis de medição do tempo, ou com aspectos cronobiológicos. Uma criança que está na rua, não tem necessariamente um relógio para ver as horas, não come quando tem fome, mas quando tem comida disponível, dorme quando se sente segura e não exatamente quando tem sono. Estes fatores provavelmente afetam o desenvolvimento da noção 
de tempo destas crianças. Esta é definitivamente uma área que requer estudo aprofundado e meticuloso.

A influência da escola no desenvolvimento cognitivo não pode ser subestimada, como afirmam Carraher e colaboradores (1985), apesar dos resultados positivos que obtiveram sobre o desenvolvimento de habilidades matemáticas de crianças trabalhadoras de rua. A perda da escolarização básica acarreta uma série de perdas de habilidades para estas crianças, especialmente com relação à linguagem. No entanto, a vivência da rua tem demonstrado uma outra forma de aprendizagem e desenvolvimento, que alguns pesquisadores chamam de "sabedoria de rua". Entre elas, a facilidade de lidar com dinheiro, de aprenderem música e habilidades computacionais. Em um Projeto de Oficina-Escola, no qual o CEP-RUA mantinha Oficinas de Matemática, observou-se que os adolescentes com baixa escolarização e história de rua, tinham mais facilidade de aprender aritmética se fossem utilizados estímulos como moedas e dinheiro em geral. Com esta estratégia tornava-se mais fácil ensinar somas e multiplicações para os adolescentes. Neste mesmo Projeto de Oficina-Escola, observou-se que os meninos aprendem com muita facilidade a trabalhar com computadores. A música, por sua vez, tem forte relação com sua criatividade. A perspectiva de participar de um festival de rap estimulou-os a aprender a escrever, para inscrever as letras de suas músicas, apresentarse e ganhar os prêmios. A utilização destas estratégias no ensino têm se revelado muito úteis com estas crianças e adolescentes.

\section{Desenvolvimento emocional de crianças em situação de rua}

Aptekar, em vários estudos, relata ter avaliado o funcionamento emocional e neurológico de meninos e meninas em situação de rua da Colômbia (1988a, 1988b, 1989, 1996). Aptekar (1989) afirma que as crianças que estão na rua apresentaram escores mais elevados em medidas de saúde mental do que crianças que permanecem em casa. $\mathrm{O}$ afastamento das crianças do ambiente hostil e estressante que encontram em 
casa pode garantir aspectos de sua saúde mental. Koller e Hutz (1996) afirmam que estas crianças não seriam indivíduos emocionalmente mais frágeis, pois o deixar a casa revela sua habilidade de reorganizar sua vida, de forma produtiva, por conta própria. Em estudos realizados pelo CEP-RUA, problemas de relacionamento familiar, abuso físico ou sexual e o desejo de buscar a "liberdade" (escapar do controle e da exploração familiar) estão entre os principais motivos que levam crianças a migrar para as ruas (Bandeira et al., 1994; Koller et al., 1996). O distanciamento de um ambiente nocivo ao desenvolvimento psicológico pode estar relacionado a um indicador de saúde mental. Porém, a não ser no delírio romântico de quem não a conhece, a rua está muito longe de se constituir num ambiente favorável a um desenvolvimento psicológico sadio.

Em estudo realizado por DeSouza, Koller, Hutz e Forster (1995), foram comparados os índices de depressão entre crianças de rua e de nível sócio-econômico baixo. Os resultados deste estudo mostraram que não há diferença entre estes grupos, ou seja, crianças de rua não são mais deprimidas do que crianças pobres que continuam vivendo com suas famílias e freqüientando escolas. Estes dados corroboram o estudo de Forster, Marcantonio e Silva (1994). As autoras solicitaram às crianças de rua que relatassem seus sofrimentos e dores. Neste estudo, as autoras não encontraram maiores índices de sofrimento psicológico declarado em crianças de rua, quando comparadas às crianças de nível sócio-econômico baixo. Partindo destas idéias, Koller, Hutz e Silva (1996) investigaram o nível de bem-estar subjetivo de crianças de rua, comparadas a crianças pobres, que viviam com suas famílias. O nível de bem-estar subjetivo de ambos os grupos não se diferenciou entre si. Os resultados confirmam os achados dos estudos anteriores sobre depressão e sofrimento e, neste caso, demonstram que o bem-estar subjetivo não está relacionado ao nível sócio-econômico ou condição de vida das pessoas. Haidt, Koller, Santos, Frohlich e Pacheco (1996) investigaram as histórias de vida de adolescentes de rua, através de relatos de emoções, como alegria, tristeza, raiva, desprezo, 
vergonha, culpa, pena e nojo. Os resultados revelam alta freqüência de eventos de risco nas trajetórias de vida destes sujeitos. No entanto, a expressão de sua sensibilidade e de suas emoções aparecem preservadas. Quando comparados com adolescentes de nível sócio-econômico baixo, observou-se que as redes de relacionamento e a competência para lidar com os eventos de risco eram mais elaboradas na amostra de rua. Os adolescentes de escola relatavam mais depressão, pensamentos conflituados, e busca de alternativas ineficazes para lidar com o stress. Os adolescentes que estavam na rua buscavam ajuda nos amigos e nas instituições, procurando apoio emocional e ajuda. Poucos relatavam buscar drogas para superar seus problemas. Os adolescentes da escola relatavam fugas de casa, brigas, uso de drogas e outras estratégias destrutivas e agressivas para lidar com os problemas imediatos. Certamente, os adolescentes que ora estão na rua, buscaram no passado uma estratégia conflituada para lidar com seus problemas, uma vez que saíram de casa. No entanto, ao que parece, a vida na rua está mostrando novas alternativas de resolução das dificuldades para eles.

Do ponto de vista emocional, a saída de casa pode representar o fracasso total do apego que um indivíduo tinha com as pessoas de sua família e desta para com ele. A falta de proteção, o sentimento de rejeição, a aparência de abandono que a criança vai revelando a cada dia na rua o confirmam. A ausência de cuidado de um adulto responsável que a ame, em quem ela possa confiar, com o qual ela se sinta segura e se identifique, podem ter profundas implicações no seu desenvolvimento emocional. Ironicamente, conforme afirmam Donald e Swart-Kruger (1994), a história relatada pela criança sobre a sua vida antes de sair de casa revelam a ausência deste apego e alta frequiência de riscos a que estava exposto dentro de sua própria casa, junto de sua família. No estudo de Reppold e colaboradores (1997), as crianças revelam que estes riscos precipitaram ou forçaram a sua saída para rua. As crianças revelam que suas casas são punitivas, hostis, perigosas e as rejeitaram. Seus pais são descritos como ausentes, doentes, desinteressados, abusivos e/ou violentos (Bandeira 
et al., 1994; Reppold et al, 1997). Koller (1994) verificou que um terço dos adolescentes de sua amostra saiu de casa porque não tolerava a ausência física do pai. Revelavam que desde que o pai se foi e eles se tornaram adolescentes, o nível de exigência e cobrança para com eles tornou-se intolerável. Relatavam, em geral, que a mãe passou a exigir que eles assumissem o sustento da família no lugar do pai, papel para o qual eles ainda não se sentiam competentes. Alguns deles referiam que saíram de casa, porque consideravam mais fácil, na sua idade, tomar conta de si próprios sozinhos na rua, do que ter que cuidar de toda a família. Da mesma forma, no estudo de Bandeira e colaboradores (1994), algumas crianças revelaram terem sido vítimas de abuso físico, abuso sexual, terem problemas de relacionamento com a família, sofrerem negligência, testemunharem violência doméstica e miséria.

Estes estudos relatam a versão de crianças que estavam na rua sobre a sua saída de casa. Foi feita uma tentativa de avaliar a visão das famílias sobre a saída das crianças de casa. Este estudo está sendo lentamente desenvolvido, devido a várias dificuldades operacionais. Houve uma tentativa inicial de executar este projeto em Porto Alegre, mas o tamanho da cidade e o número de vilas tornou difícil encontrar as famílias. Está sendo feita uma tentativa no interior do Rio Grande do Sul, em Pelotas, mas algumas dificuldades permanecem. Em geral, os endereços fornecidos pelas crianças não correspondem às suas famílias, ou estas já se mudaram do local. Estes endereços, às vezes, eram descritivos, desconhecidos e inatingíveis. Outras crianças negam-se a fornecer o endereço e expressam medo de que a família, através da equipe de pesquisadores possa encontrá-los. Outras vezes, ainda, a família encontrada nega-se a falar na criança e em seus problemas de relacionamento. Mesmo frente a todas estas dificuldades, não desistiremos deste estudo, uma vez que entendemos que estes dados possam ser muito ricos para o entendimento da realidade destes meninos e meninas e de suas famílias, subsidiando programas de prevenção da migração para a rua, ou para intervenção. Os resultados preliminares deste estudo (Recondo, Koller, Hutz, \& Equipes, 1996) revelam 
que as famílias negam que tenham mandado a criança embora de casa, mas relatam problemas de relacionamento e não escondem a miséria e as suas dificuldades de parentagem com relação a seus filhos. Alguns casos específicos indicam a necessidade de intervenção urgente nestas famílias. Por exemplo, uma mãe que ao ouvir o nome de seu filho, disse que "uma vez teve um filho com este nome, mas não sabe falar nada sobre ele e que esqueceu que ele existia". Outro caso, de um irmão mais novo do que o menino que estava na rua, que nos revelou estar sofrendo abuso sexual permanente de sua mãe e padrasto, enquanto que seu irmão revelara ter saído de casa por não tolerar ser vítima de abuso. Um outro menino que, após relatar as constantes tentativas de abuso sofridas, afirmou: "um dia tomei uma atitude de adulto e saí de casa". Esta frase ilustra a hipótese de que a saída de casa pode ser resultado de fortalecimento de um indivíduo resiliente, que prefere sair às ruas e buscar a sua própria sobrevivência do que se submeter aos abusos dentro de casa. Os irmãos que ficam podem ser mais vulneráveis do que eles. Na presença destes relatos, o CEP-RUA via-se obrigado a parar o seu trabalho de pesquisa, reavaliar suas metas e estratégias, buscar novos subsídios e buscar alternativas de intervenção.

A Tabela 3 mostra fatores de vulnerabilidade e estratégias de superação de crianças de rua, com relação ao desenvolvimento emocional.

Tabela 3. Desenvolvimento Emocional: Vulnerabilidade e adaptabilidade em crianças em situação de rua

\begin{tabular}{lll}
\hline $\begin{array}{c}\text { Área de desenvolvimento } \\
\text { EMOCIONAL }\end{array}$ & $\begin{array}{c}\text { Evidência de } \\
\text { risco ou vulnerabilidade }\end{array}$ & $\begin{array}{c}\text { Evidência de } \\
\text { adaptabilidade ou } \\
\text { estratégia }\end{array}$ \\
\hline 1. Vínculos & $\begin{array}{l}\text { perda de vínculo estável } \\
\text { com a família e com a } \\
\text { comunidade }\end{array}$ & $\begin{array}{l}\text { - vínculo com grupos ou } \\
\text { modelos relevantes da } \\
\text { comunidade }\end{array}$ \\
2. Estabilidade emocional & $\begin{array}{l}\text { ausência de relação } \\
\text { estável de proteção e } \\
\text { cuidado adulto }\end{array}$ & $\begin{array}{l}\text { - liberdade } \\
\text { autonomia }\end{array}$ \\
\hline
\end{tabular}


Nos estudos de Raffaelli e colaboradores (1997), alguns sujeitos revelam que saíram de casa, porque gostavam da rua. Relatavam experiências progressivas de ficar na rua e preferiam a ela, por causa do apoio dos amigos e por aliviarem do sofrimento em casa. Eles informam ainda que buscavam a liberdade, que é considerada por eles como um grande valor (Donald \& Swart-Kruger, 1994). Com esta liberdade eles desenvolvem um senso de autonomia e auto-confiança que pode ser positivo para o seu desenvolvimento emocional. Richter (1988) comenta que a independência propiciou um senso de auto-gerência na vida das crianças de rua que não deve ser subestimado em seus efeitos positivos sobre o seu desenvolvimento.

Os achados destas pesquisas têm sido utilizados na promoção de programas de prevenção e intervenções na comunidade. Uma alternativa para a casa que garanta a sobrevivência e a segurança para os(as) meninos(as) que estão na rua deve ser encontrada, uma vez que a rua, apesar de desenvolver alguma sabedoria não é o lugar ideal para qualquer ser humano viver.

\section{Desenvolvimento físico de crianças em situação de rua}

$\mathrm{O}$ desenvolvimento físico de crianças e adolescentes em situação de risco tem sido discutido, principalmente, em estudos relativos à área médica (nutrição, puberdade, uso de drogas etc.). No entanto, o fato de estarem expostos a tantos riscos para garantir sua segurança e integridade física, também é uma preocupação da Psicologia, especialmente no que se refere às estratégias de sobrevivência e superação de dificuldades, por eles desenvolvidas. Sabemos que crianças e adolescentes em situação de rua estão expostos à violência, doenças e acidentes, tendo maior dificuldade de ter atendimento médico para tratá-los.

Muitas vezes para obter abrigo, alimento e segurança, estas crianças usam estratégias adaptativas, como conformidade, oportunismo, reciprocidade, busca de apoio dos amigos e instituições. Donald e Swart-Kruger (1994) referem que estas crianças utilizam-se de ingenuidade para conseguir au- 
mento de renda, roupas e comidas. Neste aspecto, discordamos dos autores citados, quanto a denominação da estratégia utilizada, a qual preferimos chamar de engenhosidade. Estas crianças consistentemente descrevem estratégias elaboradas para conseguir o que precisam para sobreviver fisicamente. A ingenuidade pode ser demonstrada, entre estas estratégias, como uma forma de obter o desejado ou a agradar alguém.

A Tabela 4 apresenta aspectos do desenvolvimento físico de crianças em situação de rua, enfatizando fatores de vulnerabilidade e estratégias para garantir a sobrevivência.

Tabela 4. Desenvolvimento Físico: Vulnerabilidade e adaptabilidade em crianças em situação de rua

\begin{tabular}{|c|c|c|}
\hline $\begin{array}{c}\text { Área de desenvolvimento } \\
\text { FísICA }\end{array}$ & $\begin{array}{c}\text { Evidência de } \\
\text { risco ou vulnerabilidade }\end{array}$ & $\begin{array}{c}\text { Evidência de } \\
\text { adaptabilidade ou } \\
\text { estratégia }\end{array}$ \\
\hline 1. Abrigo & $\begin{array}{l}\text { - falta de abrigo } \\
\text { - frio e chuva }\end{array}$ & $\begin{array}{l}\text { - } \text { engenhosidade } \\
\text { - } \text { conformidade } \\
\text { - oportunismo }\end{array}$ \\
\hline 2. Segurança & $\begin{array}{l}\text { - } \text { acidentes } \\
\text { - violência }\end{array}$ & $\begin{array}{l}\text { - proteção do grupo e das } \\
\text { instituições }\end{array}$ \\
\hline 3. Nutrição & $\begin{array}{l}\text { - falta de garantia } \\
\text { de alimentação }\end{array}$ & $\begin{array}{l}\text { - } \text { conformidade } \\
\text { - engenhosidade } \\
\text { - reciprocidade }\end{array}$ \\
\hline 4. Saúde & $\begin{array}{l}\text { - uso de drogas } \\
\text { - DST/AIDS } \\
\text { - doenças não tratadas } \\
\text { - acidentes, violência }\end{array}$ & $\begin{array}{l}\text { - } \text { apoio institucional } \\
\text { - conformidade }\end{array}$ \\
\hline
\end{tabular}

Apesar do volume substancial de pesquisa na área, grande parte da qual é descritiva, há uma série de questões que ainda precisam ser investigadas para entendermos melhor o desenvolvimento desta população. Continua-se sabendo pouco sobre o desenvolvimento cognitivo destas crianças. Há poucos meses, eminentes cognitivistas, entre os quais algumas dezenas de brasileiros, reuniram-se em Geneve onde discutiu-se muito as implicações das pesquisas com chimpanzés para a teoria da mente. Porém, não há pesquisa sobre teoria 
da mente em crianças em situação de risco. Não se sabe, realmente, como crianças deste grupo entendem o mundo em que vivem, que processos utilizam para dar sentido a sua realidade, por que percebem tempo e espaço diferentemente de crianças de classe média (Hutz et al., 1995), quais são seus desejos, expectativas, temores etc. Enfim, como são essas crianças do ponto de vista psicológico, que impacto tem a socialização na rua ou em condições de vida muito precárias sobre o desenvolvimento e a cognição social? As diferenças entre crianças em situação de risco e crianças em geral são de conteúdo, de grau, ou existem diferenças qualitativas que apontam para a não-universalidade do desenvolvimento psicológico?

Seria também fundamental investigar que processos ou variáveis psicológicas protegem algumas dessas crianças, permitindo ajustamento emocional e o desenvolvimento da competência social, apesar das circunstâncias extremamente desfavoráveis em que vivem. Muitas dessas crianças não cometem crimes graves, não se tornam dependentes de drogas, e muitas vezes são capazes de aproveitar oportunidades que a sociedade ocasionalmente oferece para romper com a marginalização.

Outra linha de pesquisa importante que deveria ser aprofundada diz respeito ao estudo das famílias de crianças que migram para a rua, comparativamente a outras famílias, da mesma vila ou favela (da casa ao lado muitas vezes), cujos filhos permanecem em casa e seguem freqüentando a escola. Quais são os elementos capazes de explicar, ainda que em parte, essa diferença? Locus de controle? Expectativas de vida? Religiosidade? Sistemas de apoio social?

Não seria realmente possível tentar descrever ou listar aqui toda a multiplicidade de projetos que deveriam ou poderiam ser desenvolvidos. Para finalizar, é importante salientar que conhecimento deve ser produzido nesta área não apenas por sua relevância teórica (o que, em princípio, poderia ser uma razão suficiente). $\mathrm{O}$ conhecimento produzido por pesquisa nessa área tem alta relevância social e pode dar uma contribuição decisiva na luta para a promoção de uma sociedade 
mais justa e mais humana. Por isso mesmo, é muito grande a responsabilidade ética do pesquisador que se aventura nessa área (Hutz et al., 1995; Hutz et al., 1997). Esta é outra questão fundamental que, embora não possa ser discutida aqui, não poderia deixar de ser pelo menos mencionada.

\begin{abstract}
Issues regarding the development of street children.

Psychology and scientific research do not seem to offer satisfactory answers to many issues regarding the development of street children. Some studies argued that living on the streets is harmful or, at least, that it slows down psychological development because of the exposure of the children to addictions, violence, and exploitation. Other studies have shown that the street allows for accumulative experiences which promote a healthy development. These paradoxical findings point to the need to carry out more research in this area. Researchers at CEP-RUA/UFRGS are conducting systematic research on the emotional, cognitive and social development of street children. Our findings indicate that street children present high levels of stress and of exposure to personal and social risk. However, we have also found out that they develop skills to cope with the risk and the stress. They overcome the hazards of life on the streets using strategies that require competence and autonomy, especially strategies for establishing affective, economic and social groups through which they manage to be safer and to survive. Children in our samples did not present levels of depression or trauma higher than those of low SES children. They do not differ significantly from other groups when tested for subjective well being. Studies about life events and emotions revealed surprising stories about their life and sensitivity. Nevertheless, alternatives to a nurturing home that fosters a healthy development must be found. The street, even if it does not cause great psychological harm, is not a healthy place for human beings to live.

Key words: Street Children, Children at Risk, Development.
\end{abstract}




\section{Referências}

Aptekar, L. (1988a). Street children of Colombia. Journal of Early Adolescence, 83, 225-241.

Aptekar, L. (1988b). Colombian street children, their mental health and how they can be served. International Journal of Mental Health, 173, 81-104.

Aptekar, L. (1989). Colombian street children Gamines or Chupagruesos. Adolescence, 24, 783-794.

Aptekar, L. (1996). Crianças de rua nos países em desenvolvimento: Uma revisão de suas condições. Psicologia: Reflexão e Crítica, 9, 153-185.

Bandeira, D., Koller, S. H., Hutz, C., \& Forster, L. (1996). Desenvolvimento psico-social e profissionalização: uma experiência com adolescentes de risco. Psicologia: Reflexão e Crítica, 9, 185-207.

Barreto, M. (1991). Julgamento moral de meninos de rua. Tese de doutorado, não-publicada, Universidade Federal do Rio Grande do Sul, Porto Alegre.

Carraher, T. N., Carraher, D., \& Schliemann, A. (1985). Mathematics in the streets and in the schools. British Journal of Developmental Psychology, 3, 21-29.

DeSouza, E., Koller, S. H., Hutz, C. S., \& Forster, L. M. (1995). Preventing depression among Brazilian street children. Interamerican Journal of Psychology, 29, 261-265.

Donald, D., \& Swart-Kruger, J. (1994). The South-African street child: developmental implications. South-African Journal of Psychology, 24, 169-174.

Dryfoos,, J. G. (1990) Adolescents at risk: Prevalence and prevention. New York: Oxford University Press.

Emde, R. N. (1994). Individuality, context, and the search for meaning (Presidential Address). Child Development, 65, 719-737.

Fisher, C. B. (1993). Integrating science and ethics in research with highrisk children and youth. Social Policy Report, Volume VII, Number 4. Ann Arbor, MI: Society For Research in Child Development.

Forster, L. M., Barros, H. T., Tannhauser, S. L., \& Tannhauser, M. (1992). Meninos de rua: Relação entre abuso de drogas e atividades ilícitas [Street children: The relationship between drug use and illicit activities]. $A B P-A P A L, 14,115-120$.

Forster, L. M., Marcantonio, S., \& Silva, M. (1995). O sofrimento declarado de crianças de rua. Trabalho apresentado na XXV Reunião Anual da Sociedade Brasileira de Psicologia, Ribeirão Preto, SP.

Guimarães, M. C. S. (1994). Editorial: Ethics guidelines for FAPESPsponsored research on human populations. Brazilian Journal of Medical and Biological Research, 27, 2701-2704. 
Haidt, J., Koller, S. H., Santos, R., Frohlich, C., \& Pacheco, P. (1996). Episódios morais e temas emocionais de crianças de rua. Trabalho apresentado no Salão de Iniciação Científica da UFRGS. Porto Alegre, RS.

Huston, A. C., McLoyd, V. C., \& Coll, C. G. (1994). Children in poverty: Issues in contemporary research. Child Development, 65, 275-282.

Hutz, C. S. \& Forster, L. M. (1996). Atitudes e comportamentos sexuais de crianças de rua em Porto Alegre. Psicologia: Reflexão e Crítica, 9 , 209-229.

Hutz, C. S., Koller, S. H., Bandeira, D. R., \& Forster, L. M. (1995). Methodological and ethical issues in research with street children. Trabalho apresentado no the Society for Research in Child Development Convention, Indianapolis, IN. (ERIC Document Reproduction Service No. PS 023 280).

Hutz, C. S., Koller, S. H., Bandeira, D. R., \& Forster, L. M. (1997). Social and demographic characteristics of street children in Southern Brazil. Manuscrito submetido para publicação.

Jessor, R. (1993). Successful adolescent development among youth in high-risk settings. Special Issue: Adolescence.American Psychologist, 48, 117-126.

Kazdin, A. E. (1993). Adolescent mental health: Prevention and treatment programs. American Psychologist, 48, 127-141.

Koller, S. (1994). Julgamento moral pró-social de meninos e meninas de rua. Tese de Doutorado, não-publicada, Pontifícia Universidade Católica do Rio Grande do Sul, Porto Alegre.

Koller, S. H., \& Hutz, C. (1996). Meninos e meninas em situação de rua: Dinâmica, diversidade e definição. Coletâneas da ANPEPP, 1(12), 11-34.

Koller, S. H., Hutz, C., \& Silva, M. (1996). Subjective well-being in Brazilian street-children. Trabalho apresentado no XXVI International Congress of Psychology. Montreal, Canadá.

Kuschick, M., Reppold, C., Dani, D., Raffaelli, M., \& Koller, S. H. (1996). A visão dos meninos e meninas de rua sobre sua situação de vida. Trabalho apresentado na XXVI Reunião Anual da Sociedade Brasileira de Psicologia. Ribeirão Preto, SP.

Marguerat, Y. (1989). Reflexions sur les problematiques de la prevention de la delinquence juvenile en Afrique Noire. Revue Internationale de Criminologie et de Police Technique, 42, 208-213.

McKirnan, D. J., \& Johnson, T. (1986). Alcohol and drug use among "street" adolescents. Addictive behaviors, 11, 201-205.

Raffaelli, M., Koller, S., Bandeira, D., Reppold, C., Kuschick, M. \& Dani, D. (1997). Exploring the lives of Brazilian street youth using a sentence completion task and structured interview. Trabalho aceito para apresentação na Urban Childhood Conference, Norway. 
Raffaelli, M., Koller, S. H., Reppold, C., Kuschik, M., \& Bandeira, D. (1997). O gostar da rua: Relatos das crianças que vivem na rua. Manuscrito não-publicado.

Recondo, N., Koller, S., Hutz, C., \& Equipes (1996). Crianças de rua e família. Manuscrito não-publicado.

Reppold, C., Kuschick, M., Santos, C., Raffaelli, M., Bandeira, D., \& Koller, S. (1997). Les relations familiales et la trajectoire d'enfants et adolescents dans les rues du Brésil. Manuscrito submetido para publicação.

Richter, L. (1988). Street children: The nature and scope of the problem in Southern Africa. The Child Care Worker, 6, 11-14.

Silva, M.R., Silva, A.S., Santos, C.L., Reppold, C.T, Alves, P.B., \& Koller, S. (1996). O cotidiano e a rua - Atividades de crianças em situação de rua na cidade de Porto Alegre. Trabalho apresentado na XXVI Reunião Anual da Sociedade Brasileira de Psicologia. Ribeirão Preto, SP.

Silva, A., Weber, L., Raimundo, M., Bandeira, D., \& Koller, S. (1996). Como crianças de nível sócio-econômico médio e em situação de rua desenham uns aos outros? Trabalho apresentado no XXVI Reunião Anual da Sociedade Brasileira de Psicologia. Ribeirão Preto, SP.

Tyler, F. B., Holliday, M. Y., Tyler, S. L., Echeverry, J. J., \& Zea, M. C. (1987). Street children and play. Children's Environments Quarterly, 4, 13-17.

Claudio Simon Hutz e Sílvia Helena Koller são doutores em Psicologia, respectivamente, pela University of Iowa e pela Pontifícia Universidade Católica do Rio Grande do Sul/Arizona State University, e professores do Curso de PósGraduação em Psicologia do Desenvolvimento, da Universidade Federal do Rio Grande do Sul. Endereço para correspondência: CEP-RUA, CPG Psicologia, UFRGS, Rua Ramiro Barcelos, 2600, 90035-003, Porto Alegre, RS. 